\title{
A Nonparasitic Liver Cyst Presenting as a Klatskin Tumor
}

Nonparasitic solitary liver cysts are not infrequently encountered in surgery, but are often asymptomatic. The symptoms usually consist of vague upper abdominal discomfort, nausea, vomiting or dull pain $(1,2)$. Obstructive jaundice has been reported in polycystic liver disease and, with low incidence, in solitary liver cysts. We report a patient with a solitary liver cyst who developed persistent obstructive jaundice due to bile duct obstruction. The cyst had been drained nearly one year prior to the patient presenting to our gastroenterology department. Cytology of the aspirated fluid was equivocal at the time, and the patient's symptoms resolved. The patient presented to our facility several months later with weight loss and jaundice. The laboratory data was consistent with obstructive jaundice. Endoscopic retrograde cholangiopancreatography (ERCP) demonstrated a stricture at the level of the bifurcation of the common hepatic duct which had the appearance of a Klatskin tumor (Figure 1). The operative findings consisted of a solitary liver cyst compressing the bifurcation of the common hepatic duct.

The incidence of solitary liver cysts has been reported to be 16 per 10,000 abdominal surgeries at the Mayo Clinic (1). The incidence of obstructive jaundice in nonparasitic liver cysts is estimated to be $5-9 \%$ and, usually, is due to compression of the extrahepatic system $(1,3-5)$. Other reports have identified calculi, cystic malformation, or kinking of the common duct as causes for obstruction in patients with solitary cysts $(1,4)$. Direct compression of the common hepatic duct by a nonparasitic solitary liver cyst has not been reported previously. In the evaluation of a patient with obstructive jaundice or, in particular, suspected cholangiocarcinoma, liver cysts may deserve consideration in the differential diagnosis.

\section{References}

1 Jones WL, Montain JC, Warren KW: Symptomatic nonparasitic cysts of the liver. Br. J. Surgery 1974; 1974: 118-123.

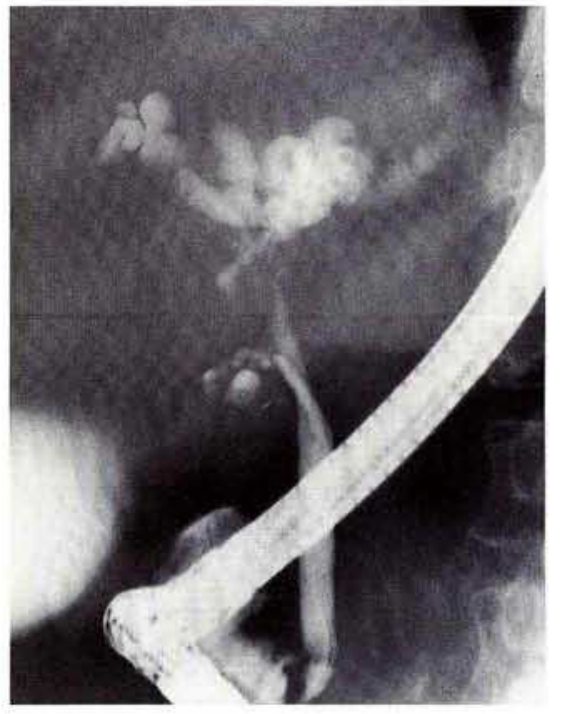

Figure 1:

ERCP radiograph illustrating external compression at the proximal common hepatic duct, mimicking the appearance of a Klatskin tumor.

2 Santiman FW: Intermittent jaundice: a rare complication of a solitary nonparasitic cyst. Gastroenterology 1977; 73: 325-328.

3 Sanfelippo PM, Beahr OH, Weeland LH: Cystic disease of the liver. Ann. Surg. 1974; 179: 922.

4 Lai ELS, Wong J: Symptomatic nonparasitic cysts of the liver. World J. Surg. 1990; 14: 452-456.

5 Machell RJ, Calne RY: Solitary cysts presenting with jaundice. $\mathrm{Br}$ J. Radiol. 1975; 51: 631-632.

J. Byrne, K. Balasubramanian, C. Garberoglio Department of Internal Medicine and Department of Surgery, Section of Gastroenterology, School of Medicine, Loma Linda University 11234 Anderson Street, California CA 92350, USA 